\title{
NUMERICAL MODELLING OF SELF-HEATING EFFECTS ON GUIDING MODES OF HIGH-POWER PHOTONIC CRYSTAL FIBRE LASERS
}

\author{
L. Mousavi a ${ }^{\text {a }}$ M. Sabaeian ${ }^{\mathrm{b}}$, and H. Nadgaran ${ }^{\mathrm{c}}$ \\ a Department of Physics, Dezful Branch, Islamic Azad University, Dezful, Iran \\ ${ }^{\mathrm{b}}$ Department of Physics, Faculty of Science, Shahid Chamran University of Ahvaz, Ahvaz, Iran \\ ${ }^{c}$ Department of Physics, College of Science, University of Shiraz, Shiraz 71454, Iran \\ E-mail: sabaeian@scu.ac.ir
}

Received 24 June 2012; revised 21 October 2012; accepted 20 June 2013

\begin{abstract}
The influence of heat generation on propagating modes in a high-power large-mode-area photonic crystal fibre laser was investigated. The temperature distribution, temperature gradient, thermally induced stresses were first simulated. Then the Maxwell's wave equation with taking the thermal refractive index tensor into account was solved to observe the effects of heat on propagating modes. The results show sensible modifications for TE, TM, and EH mode profiles. However, the linear polarized fundamental mode (HE) was not affected under thermal effects.
\end{abstract}

Keywords: thermal effects, photonic crystal fibre laser, thermal dispersion, thermal stress

PACS: 42.55.Tv, 42.60.JF, 44.10.+i

\section{Introduction}

Photonic crystal fibre lasers (PCFLs) that are also called holey fibre lasers or microstructure fibre lasers have gained much interest due to their ability in generating high power outputs with considerable stability, excellent beam quality, compactness, and maintenance ease $[1,2]$. The general structure of such fibres consists of air holes arranged in a twodimensional triangular pattern running through the whole fibre length. One or more missing holes usually form a solid fibre core surrounded by holey cladding. The ratio of the hole diameter $(d)$ to the hole-to-hole distance $(\Lambda)$ plays a crucial role in determining the optical properties of photonic crystal fibres (PCFs). It has been proved that for a ratio of $d / \Lambda=0.45$ the one-hole missing PCF acts as a single-mode fibre regardless of the wavelength of the propagating light [3-5]. In fibre lasers, to suppress unwanted nonlinear effects when scaling the delivered powers, one can increase the core area. This scheme, however, may convert the single-mode fibre to a multi-mode fibre. This phenomenon is not desired because of reduction of beam quality. To overcome this problem, the numerical aperture must be reduced from standard values of 0.1 to a small value of 0.06 [6]. This value for the numerical aperture allows a core diameter of about $15 \mu \mathrm{m}$ in the $1 \mu \mathrm{m}$ wavelength region [6]. In this regard $2.3 \mathrm{~m}$ long ytterbium-doped air-clad large-modearea fibre lasers have been reported to deliver $80 \mathrm{~W}$ output power equivalent to the power density of $35 \mathrm{~W} / \mathrm{m}$ [7]. Also, for a $4 \mathrm{~m}$ length fibre, a pump of $360 \mathrm{~W}$ delivering the output power of $260 \mathrm{~W}$ was reported [8].

Although a large surface-to-volume ratio of fibres can ease heat dissipation from the fibre surface compared to bulk lasers, however in high powers the heat transfer mechanisms cannot be such effective [8-10]. Accordingly, active cooling systems must be used. In a $7 \mathrm{~cm}$ short fibre laser, the thermal effects of a heat load density of $\sim 200 \mathrm{~W} / \mathrm{m}$ was 
so influential that the fibre laser had to be cooled actively by water [11].

The generation of heat in a small region of the core where active ions are present can cause a severe temperature gradient. A temperature gradient built up throughout the fibre cross-section induces refractive index modification via two well-known phenomena: thermal dispersion or $\mathrm{d} n / \mathrm{d} T$ effect, and thermally induced stresses leading to birefringence. Markos et al. simulated the change of the effective refractive index, $\Delta n_{\text {eff }}$ and the effective mode area as a function of fibre temperature in a hybrid PDMS/silica PCF [12]. Jansen et al. recently simulated and experimentally confirmed the thermal dispersion effects on very large-mode-area PCFLs [13]. Sabaeian et al. investigated the thermal dispersion effects on the core confinement factor (CCF) of a double-clad octagonal fibre laser [9]. The results were interesting in the CCF due to thermal lensing that increases the cladding mode overlapping in the core region. Furthermore, one can name other thermal effects such as thermally induced phase mismatching [14], thermal modal instability [15], and depolarization loss [16].

In high-power PCFLs, one should be aware of consequences of induced heat in designing and constructing such systems. A huge contrivance must be used when the pump power is increased to high values. This is because of thermal fracture, core melting, and thermal lensing that can prevent power scalation together with influences on mode propagation and efficiency [17]. Dawson et al. re1ported the limitation of peak intensity of fibre laser output due to thermal effects [18].

This work inspects the heat generation effect on the mode characteristics of a solid-core photonic crystal fibre laser. To generalize our modelling, the thermal dispersion and thermally induced stress effects will be taken into account for the first time. The latter is often ignored in literature $[8,9,12,13$, 17]. Our fibre laser is an air-clad ytterbium-doped large-mode-area one used already by Limpert et al. [8]. The core has been established with three holes missing in the triangular lattice round the inner clad. The second clad is formed by an air chamber consisting of the stretched holes with silica bridges round the first clad. Finally a thin acrylate layer surrounds the fibre. Figure 1 shows the electron microscope image of our large-mode-area PCFL. To the best of our knowledge, this work is the first to reveal the role of air-holes in claddings and - disapproving any simplifications in the literature - not to use average values of thermal conductivity anymore, that is, the real geometry for the holey fibre in our calculations is the key point of this work [19].

In this work we first calculate the temperature distribution, temperature gradient, and thermally induced stresses across the fibre as a function of heat load density $(\mathrm{W} / \mathrm{m})$. Then, using the Maxwell's wave equation, the electric fields are simulated including the refractive index as a tensor quantity. In our previous work [9], we did not consider the tensor property of the refractive index. So, we solved the scalar Maxwell's wave equation. Due to a complex structure of the holey fibre, the numerical method of finite element is adopted to raise the reliability of the results.

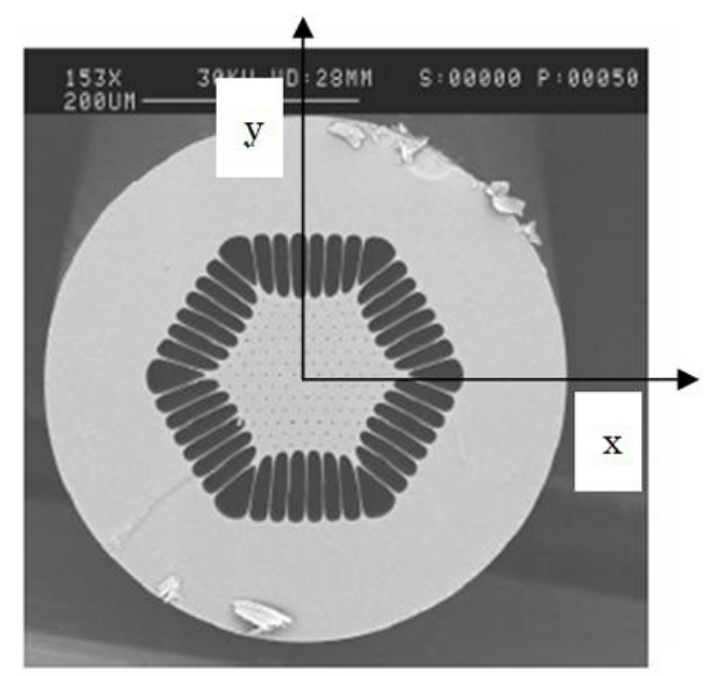

Fig. 1. Scanning electron microscope image of the large-mode-area PCFL with $x-y$ axes [8].

\section{Temperature distribution}

Heat is generated mainly in the rare-earth-doped core due to quantum defect, non-unity quantum efficiency, and non-radiative processes [9]. Then it is transferred to the fibre surface by heat conduction. From surface to ambient, radiation and convection are the main responsible mechanisms for heat dissipation. The temperature distribution within the PCFL in the steady-state regime can be calculated by the heat conduction equation [9]

$$
-\vec{\nabla} \cdot[K(T) \vec{\nabla} T(x, y)]=Q(x, y),
$$


where $T(x, y)$ is temperature in Kelvin, $K(T)$ is temperature dependent thermal conductivity in $\mathrm{W} / \mathrm{m} / \mathrm{K}$, and $\mathrm{Q}(x, y)$ is heat source density in $\mathrm{W} / \mathrm{m}^{3}$. Although temperature independent thermal conductivity may suffice $[8,9,19,20]$, in this work we have used the experimental data of Jund and Jullien [21] to comprehensively cover the temperature dependence of thermal conductivity.

For the fibre core we consider $Q=P_{\mathrm{h}} /\left(\pi \alpha^{2}\right)$ as the heat source density where $P_{\mathrm{h}}$ is heat load per meter, and $\pi \alpha^{2}$ is the average core area. The source term for claddings and fibre cover was taken to be zero in Eq. (1).

The most general boundary condition for temperature at the fibre surface is [22]

$$
-K \frac{\partial T}{\partial r}=h\left(T-T_{\infty}\right)+\varepsilon \sigma\left(T^{4}-T_{\infty}^{4}\right),
$$

where $h$ is the heat convection coefficient having a typical value for cooling with air as $h=17 \mathrm{w} / \mathrm{m}^{2} / \mathrm{K}$, $T_{\infty}=298 \mathrm{~K}$ is ambient temperature, $\varepsilon=0.95$ [8] is fibre emissivity, and $\sigma=5.6705 \times 10^{-8} \mathrm{~W} / \mathrm{m}^{2} / \mathrm{K}^{4}$ is the Stefan-Boltzmann constant.

The geometrical specifications of our fibre are [8]: core diameter $20 \mu \mathrm{m}$, hole diameter $d=1.64 \mu \mathrm{m}, d / \Lambda=0.18$, diameter of the first cladding $150 \mu \mathrm{m}$ (hexagonal), diameter of the second cladding $440 \mu \mathrm{m}$, and coating thickness $20 \mu \mathrm{m}$. The thermo-optical properties of silica, acrylate, and air are listed in Table 1.

Figure 2 shows the temperature distribution across the PCFL for $P_{\mathrm{h}}=10 \mathrm{~W} / \mathrm{m}$. The Figure shows high temperatures for the core as we expected. An inspection of the Figure reveals that the small airholes have not any noticeable effect on temperature distribution across the PCFL. This can be seen much better in Fig. 3 where we plotted a quantitative graph.

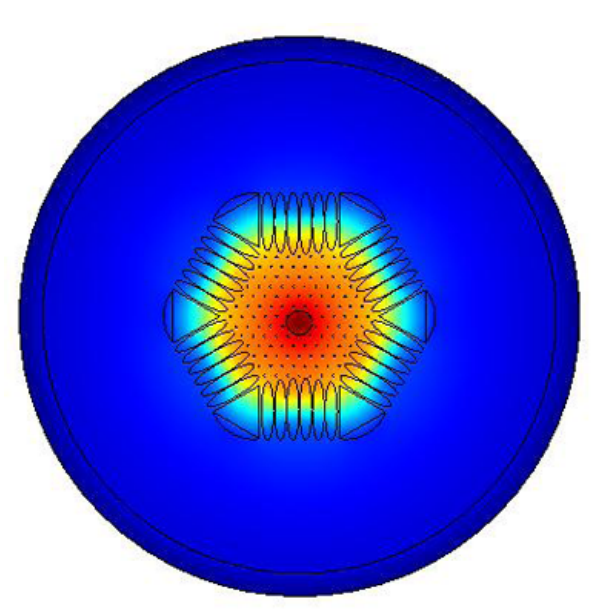

Fig. 2. Temperature distribution over the fibre cross-section for $P_{\mathrm{h}}=10 \mathrm{~W} / \mathrm{m}$.

Figure 3 shows the 2D temperature distribution along the $\mathrm{x}$ direction. From this Figure, one can see the maximum temperature is $430.5 \mathrm{~K}$ at the core centre. At the fibre surface, the temperature reaches $425 \mathrm{~K}$. To get a better insight into temperature variation over the fibre cross-section, in Fig. 4 we calculated the temperature gradient over the fibre cross-section for $P_{\mathrm{h}}=10 \mathrm{~W} / \mathrm{m}$.

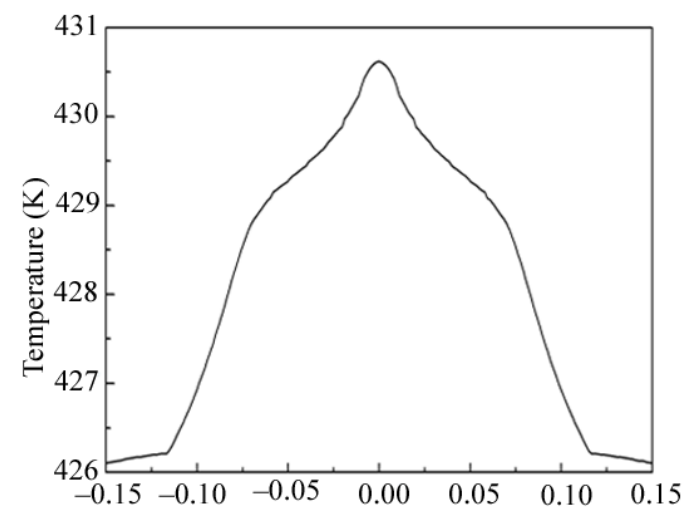

Fig. 3. Temperature distribution along $x$ direction for $P_{\mathrm{h}}=10 \mathrm{~W} / \mathrm{m}$.

Table 1. Thermo-optical properties of silica, acrylate, and air.

\begin{tabular}{ccc}
\hline Property & Silica & Reference \\
\hline Silica thermal conductivity & $1.38 \mathrm{~W} / \mathrm{m} / \mathrm{K}$ & {$[8]$} \\
\hline Acrylate thermal conductivity & $0.2 \mathrm{~W} / \mathrm{m} / \mathrm{K}$ & $[1]]$ \\
\hline Air thermal conductivity & $2.58 \times 10^{-2} \mathrm{~W} / \mathrm{m} / \mathrm{K}$ & {$[23]$} \\
\hline Heat transfer coefficient & $17 \mathrm{~W} / \mathrm{m}^{2} / \mathrm{K}$ & {$[19]$} \\
\hline Silica Young's modulus & $72.5 \mathrm{GPa}$ & {$[23]$} \\
\hline Acrylate Young's modulus & $1.2 \mathrm{GPa}$ & {$[23]$} \\
\hline Silica Poisson's ratio & 0.17 & {$[23]$} \\
\hline Acrylate Poisson's ratio & 0.452 & {$[23]$} \\
\hline
\end{tabular}




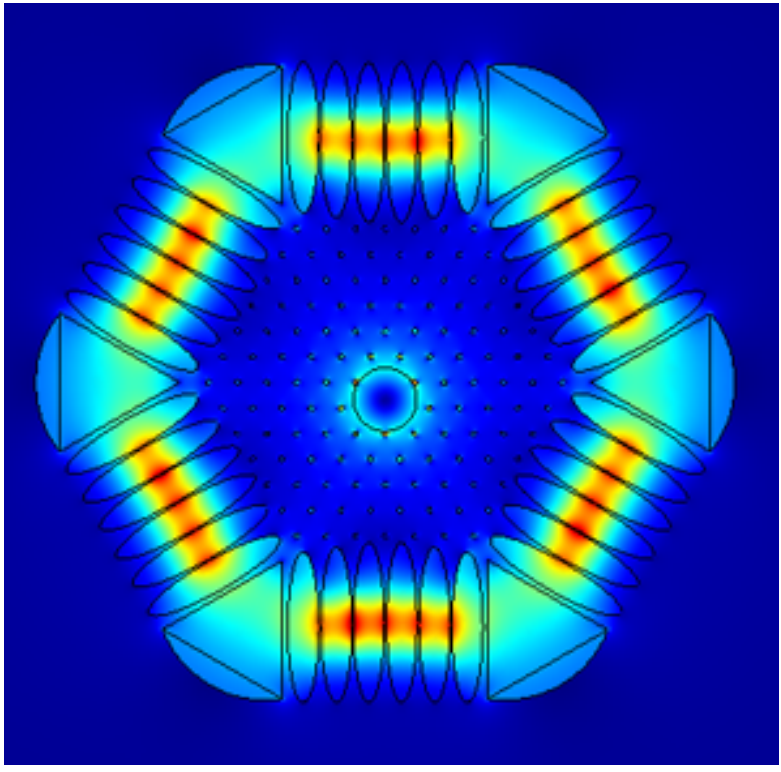

Fig. 4. Temperature gradient distribution across the fibre for $P_{\mathrm{h}}=10 \mathrm{~W} / \mathrm{m}$.

As Figure shows, there are two zones at which the temperature gradient is high: around the core boundary and on the middle part of the second cladding where the big holes exist. As one can foresee, the higher temperature gradient causes the stronger thermal stresses. Strong stresses may result in destruction of glass bridges, the spacing between neighbouring holes. Figure 5 provides a quantitative insight into the temperature gradient, that is, a $2 \mathrm{D}$ curve for the temperature gradient along $\mathrm{x}$ axis is drawn.

This Section is concluded with the temperature of the fibre core as a function of heat load $(\mathrm{W} / \mathrm{m})$ for two heat transfer coefficients. The values of

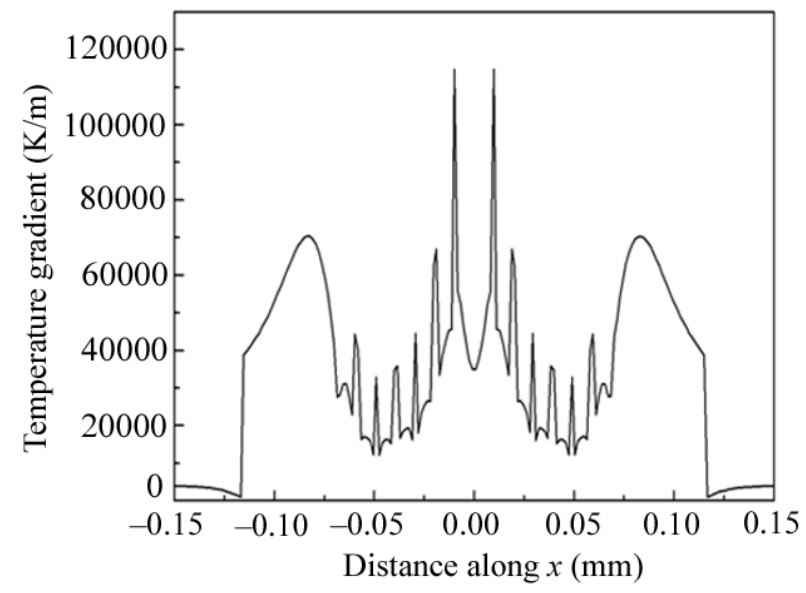

Fig. 5. Temperature gradient along $\mathrm{x}$ direction for $P_{\mathrm{h}}=10 \mathrm{~W} / \mathrm{m}$. $h=17 \mathrm{~W} / \mathrm{m}^{2} / \mathrm{K}$ and $h=350 \mathrm{~W} / \mathrm{m}^{2} / \mathrm{K}$ were set for air cooling and water cooling, respectively [19]. The active cooling (water cooling) yields a noticeably lower core temperature compared to air cooling.

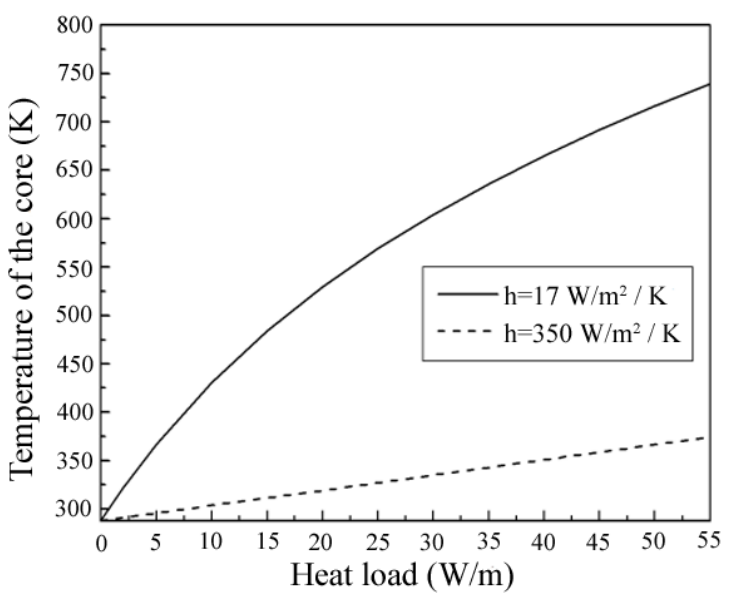

Fig. 6. Temperature of the core as a function of the heat load for two heat transfer coefficients.

\section{Thermally induced stresses}

The thermally induced stresses (or strains) are calculated using the equilibrium equation given by [24]

$$
\frac{1-v}{1+v} \vec{\nabla}(\vec{\nabla} \cdot \vec{u}) \frac{1-2 v}{1+v} \vec{\nabla} \times(\vec{\nabla} \times \vec{u})=\alpha_{\mathrm{T}} \vec{\nabla} T,
$$

where $v$ is the Poisson's ratio and $\alpha_{\mathrm{T}}$ is the thermal expansion coefficient. The solution of above equation gives the displacement vector components $\left(u_{x}, u_{y}, u_{z}\right)$. The first derivatives of displacement vector components define the strain tensor components as

$$
\varepsilon_{k l}=\frac{1}{2}\left(\frac{\partial u_{k}}{\partial x_{l}}+\frac{\partial u_{l}}{\partial x_{k}}\right)
$$

Using the generalized Hooke's law [25], $\sigma_{i j}=C_{i j k l} \varepsilon_{k l}$, where $\sigma_{i j}$ are the stress tensor components and $C_{i j k l}$ are the stiffness tensor components, one can calculate the stress components. In the plane strain approximation which is used for longlength warmed up systems with a zero temperature gradient along the $z$ direction, the nonzero components of the strain tensor are $\varepsilon_{1}=\varepsilon_{x x}, \varepsilon_{2}=\varepsilon_{y y}$, and $\varepsilon_{6}=\varepsilon_{x y}$. Under this approximation and for an 
isotropic structure such as glassy fibre, the nonzero components of the stress tensor are $\sigma_{1}, \sigma_{2}, \sigma_{3}\left(=\sigma_{z z}\right)$, and $\sigma_{6}$. Also, for glassy media only three stiffness components are independent [25]: $C_{11}=E(v-1) /$ $\left(2 v^{2}+v-1\right), C_{12}=-E v /\left(2 v^{2}+v-1\right)$, and $C_{44}=E /(v-1)$, where $E$ is the Young's modulus.

Figure 7 shows the distribution of $\sigma_{x x}$ for $10 \mathrm{~W} / \mathrm{m}$ heat load. In stress calculations, the airholes subdomains have been omitted because the Young's modulus for air is not defined. The light colour zones show the compressive stress while dark colour shows a tensile one. Strong stresses are obvious near the air-hole especially for the second cladding. The tendency of inner fibre zones for expansion leads to compressive stresses.

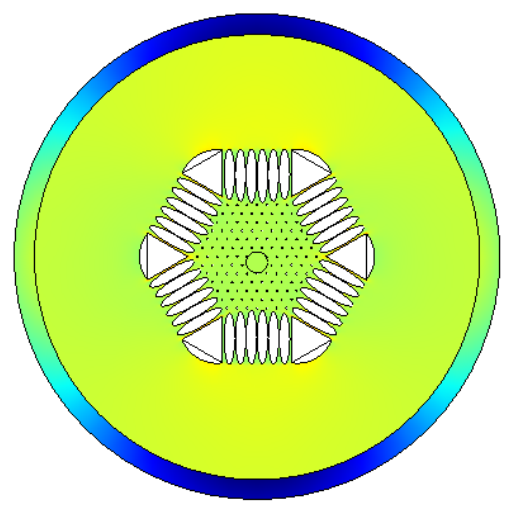

Fig. 7. Distribution of $x$ component of thermal stress $\left(\sigma_{\mathrm{xx}}\right)$ for $P_{\mathrm{h}}=10 \mathrm{~W} / \mathrm{m}$.

Figures 8 and 9 show $2 \mathrm{D}$ curves of $\sigma_{x x}$ and $\sigma_{y y}$ for $P_{\mathrm{h}}=10 \mathrm{~W} / \mathrm{m}$ heat load, respectively. For the core and the inner cladding, the stress reaches about $10 \mathrm{MPa}$, while for the second cladding the stress shows values of about $44 \mathrm{MPa}$. As the Figures show, the stress grows quickly in the glassy spacing between neighbouring air-holes and then vanishes quickly at the holes' boundaries.

\section{Propagating modes}

Once the temperature distribution and the thermally induced stresses are found, components of the refractive index tensor can be calculated easily. The tensor property of the refractive index in warmed up media is induced by thermal stresses. Additional terms are comprised of two terms: ther-

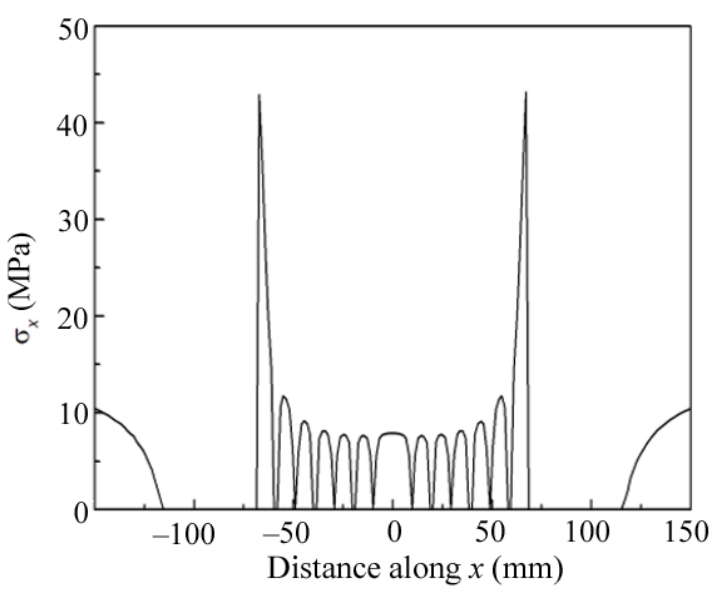

Fig. 8. The $x$ component of thermal stress along $x$ direction for $P_{\mathrm{h}}=10 \mathrm{~W} / \mathrm{m}$.

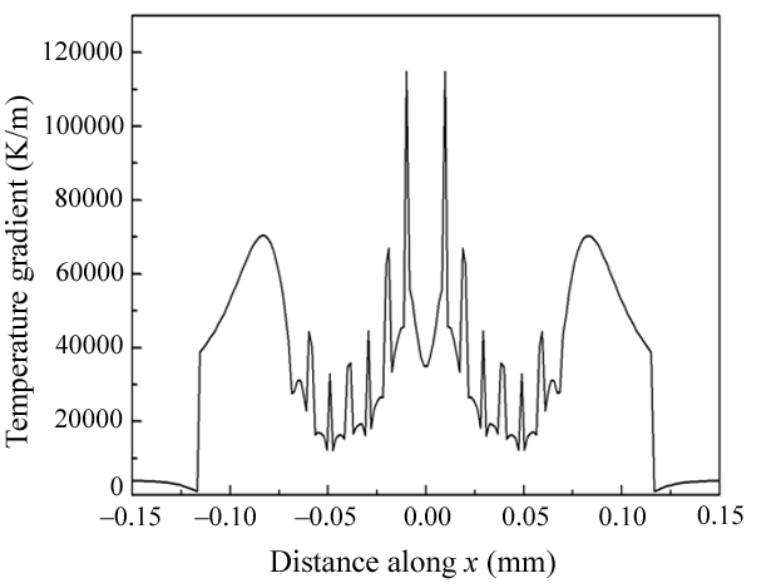

Fig. 9. The $y$ component of thermal stress along $x$ direction for $P_{\mathrm{h}}=10 \mathrm{~W} / \mathrm{m}$.

mal dispersion and photo-elastic effect. The former is isotropic and the latter is anisotropic. Various components of the refractive index tensor are given by [26]:

$$
n_{i j}=n_{0}+\frac{\partial n}{\partial T}\left(T-T_{0}\right)+\sum_{k, l=1}^{2} B_{i j k l} \sigma_{k l},
$$

where the first term, $n_{0}$, is the glass refractive index at the ambient temperature without exerting any additional stress, the second term is the thermal dispersion contribution [9], and the third term is the photo-elastic contribution. $B_{i j k l}$ are the components of the fourth rank stress-optic tensor [20]. After some algebraic treatment, Eq. (5) yields the following expressions: 


$$
\begin{aligned}
& n_{x x}=n_{0}+\frac{\partial n}{\partial T}\left(T-T_{0}\right)-\frac{n_{0}^{3}}{2}\left[B_{\|} \sigma_{x}+B_{\perp}\left(\sigma_{y y}+\sigma_{z z}\right)\right], \\
& n_{y y}=n_{0}+\frac{\partial n}{\partial T}\left(T-T_{0}\right)-\frac{n_{0}^{3}}{2}\left[B_{\|} \sigma_{y y}+B_{\perp}\left(\sigma_{x x}+\sigma_{z z}\right)\right], \\
& n_{z z}=n_{0}+\frac{\partial n}{\partial T}\left(T-T_{0}\right)-\frac{n_{0}^{3}}{2}\left[B_{\perp}\left(\sigma_{x x}+\sigma_{y y}\right)+B_{\|} \sigma_{z z}\right], \\
& n_{x y}=-\frac{n_{0}^{3}}{2}\left[B_{\perp}-B_{\|}\right] \sigma_{x y},
\end{aligned}
$$

where $B_{\|}$and $B_{\perp}$ are the parallel and perpendicular stress-optics coefficients [20].

To see the effects of heat load on guiding modes, the electromagnetic wave equation is needed to be solved with taking the refractive index tensor into account. For an inhomogeneous (coordinates dependent refractive index) and anisotropic medium, the Maxwell's wave equation leads to [9]

$$
\nabla^{2} \psi_{m n}+\frac{c^{2}}{\omega^{2}} n^{2} \cdot \psi_{m n}=-\nabla\left(\frac{\nabla n^{2}}{n^{2}} \cdot \psi_{m n}\right)
$$

where $y(x, y)$ is the profile of the propagating mode defined as:

$$
E(x, y, z)=E_{0} \psi(x, y) \mathrm{e}^{-\mathrm{i} b z},
$$

with $\beta$ as the propagation constant.

Figure 10(a) shows the simulated result for the $\mathrm{TE}_{01}$ mode without thermal effects. Figure 10(b) shows the same mode under $P_{\mathrm{h}}=50 \mathrm{~W} / \mathrm{m}$ heat load.
The contour plots are also accompanied for getting better insights. The electric field is pulled into the core region that can be attributed to the thermal lensing. Moreover, the electric field is no longer azimuthally symmetric blaming thermal stresses. The 2D curves in Fig. 11 obtained from normalization of electric field over the whole fibre cross-section shows the $\mathrm{TE}_{01}$ mode profiles when heat load is neglected (solid curve) and when it is considered (dashed and dotted curves). Therefore, consideration of refractive index variation due to heat load leads to sensible modifications of the electric field profile.

Similar results were obtained for $\mathrm{TM}_{01}$ and $\mathrm{EH}_{21}$ modes. However for the $\mathrm{HE}_{11}$ mode, which is the fundamental fibre mode, we did not see any noticeable changes on the electric field profile. This may be due to the linear polarization of the fundamental mode that is not affected by thermally induced anisotropic media.

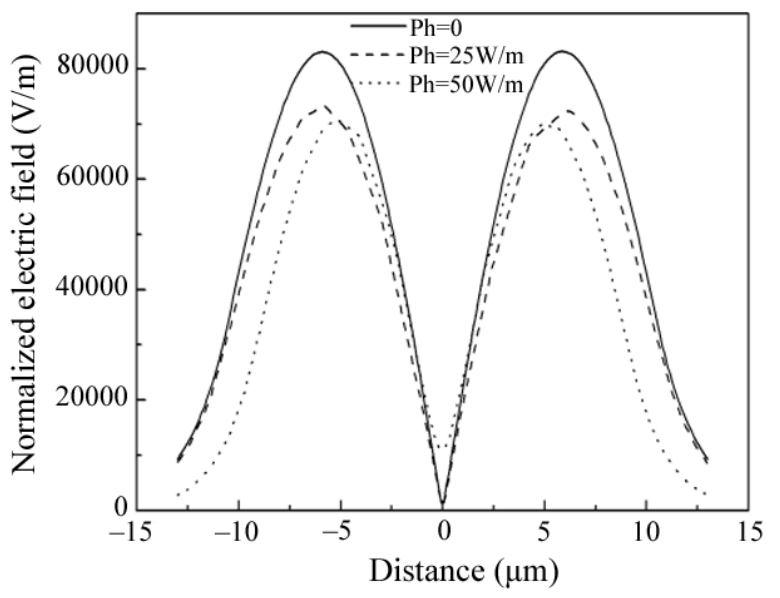

Fig. 11. The normalized electric field profile along $x$ direction for $\mathrm{TE}_{01}$ mode.

(b)

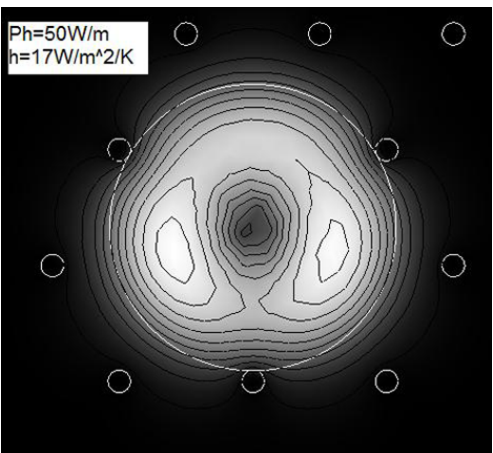

Fig. 10. The contour plot of $\mathrm{TE}_{01}$ mode for (a) $P_{\mathrm{h}}=0$ and (b) $P_{\mathrm{h}}=50 \mathrm{~W} / \mathrm{m}$. 


\section{Conclusion}

In this work the effects of heat load in the active core of a double clad photonic crystal fibre laser were investigated numerically. The temperature distribution, temperature gradient, and thermally induced stresses were simulated versus heat load density. In thermal calculations the convection and in particular the radiation that is usually ignored in the literature have been taken into account. PCFL guiding modes then were simulated under a thermally modified refractive index. The results showed strong thermal stresses for glass bridges between air-holes constituting the second cladding. Under thermal effects, the $\mathrm{TE}_{01}, \mathrm{TM}_{01}$, and $\mathrm{EH}_{21}$ modes suffered modifications relative to the non-thermal model. The linear polarized HE mode, however, was seen not to be affected by heat load even for $50 \mathrm{~W} / \mathrm{m}$.

We conclude that the thermal effects can destroy the standard shape of PCFL modes and so lead to the degradation of beam quality. Calculation of $\mathrm{M}^{2} \mathrm{fac}-$ tor under heat load is the future work of the authors.

\section{Acknowledgment}

L. Mousavi and M. Sabaeian would like to thank Islamic Azad University Dezful Branch and Shahid Chamran University of Ahvaz for financial support.

\section{References}

[1] W.J. Wadsworth, R.M. Percival, G. Bouwmans, J.C. Knight, and P.St.J. Russell, High power air-clad photonic crystal fibre laser, Opt. Express 11, 48-53 (2003).

[2] L. Michaille, C.R. Bennett, D.M. Taylor, T.J. Shepherd, J. Broeng, H.R. Simonsen, and A. Petersson, Phase locking and supermode selection in multicore photonic crystal fiber lasers with a large doped area, Opt. Lett. 30, 1668-1670 (2005).

[3] N.A. Mortensen, J.R. Folkenberg, M.D. Nielsen, and K.P. Hansen, Modal cutoff and the $V$-parameter in photonic crystal fibers, Opt. Lett. 28, 1879-1881 (2003).

[4] N.A. Mortensen, M.D. Nielsen, J.R. Folkenberg, A. Petersson, and H.R. Simonsen, Improved largemode-area endlessly single-mode photonic crystal fibers, Opt. Lett. 28, 393-395 (2003).

[5] T.A. Birks, J.C. Knight, and P.St.J. Russell, Endlessly single-mode photonic crystal fiber, Opt. Lett. 22, 961-963 (1997).
[6] J. Limpert, O. Schmdt, J. Rothhardt, F. Röser, T. Schreiber, A. Tünnermann, S. Ermeneux, P. Yvernault, F. Salin, Extended single-mode photonic crystal fiber lasers, Opt. Express 14, 27152720 (2006).

[7] J. Limpert, T. Schreiber, S. Nolte, H. Zellmer, T. Tünnermann, R. Iliew, F. Lederer, J. Broeng, G. Vienne, A. Petersson, and C. Jakobsen, Highpower air-clad large-mode-area photonic crystal fiber laser, Opt. Express 11, 818-823 (2003).

[8] J. Limpert, T. Schreiber, A. Liem, S. Nolte, H. Zelmer, T. Peschel, V. Guyenot, and A. Tünnermann, Thermo-optical properties of airclad photonic crystal fiber lasers in high-power operation, Opt. Express 11, 2982-2990 (2003).

[9] M. Sabaeian, H. Nadgaran, M. De Sario, L. Mecia, and F. Prudenzano, Thermal effects on double clad octagonal Yb:glass fibre laser, Opt. Mater. 31, 1300 (2009).

[10]Y. Jeong, S. Baek, P. Dupriez, J.-N. Maran1, J.K. Sahu1, J. Nilsson1, and B. Lee, Thermal characteristics of an end-pumped high-power ytterbium-sensitized erbium-doped fiber laser under natural convection, Opt. Express 16, 19865-19871 (2008).

[11]T. Qui, L. Li, A. Schulzgen, V.T. Temyanko, T. Luo, S. Jiang, A. Mafi, J.V. Moloney, and N. Peyghambarian, Generation of $9.3-\mathrm{W}$ multimode and 4-W single-mode output from $7-\mathrm{cm}$ short fiber lasers, IEEE Photon. Technol. Lett. 16, 2592-2594 (2004).

[12]Ch. Markos, K. Vlachos, and G. Kakarantzas, Bending loss and thermo-optic effect of a hybrid PDMS/silica photonic crystal fiber, Opt. Express 18, 24344-24351 (2010).

[13]F. Jansen, F. Stutzki, H.-J. Otto, T. Eidam, A. Liem, C. Jauregui, J. Limpert, and A. Tünnermann, Thermally induced waveguide changes in active fibers, Opt. Express 20, 3997-4008 (2012).

[14]M. Sabaeian, L. Mousave, and H. Nadgaran, Investigation of thermally-induced phase mismatching in continuous-wave second harmonic generation: A theoretical model, Opt. Express 18, 18732-18743 (2010).

[15]B. Ward, C. Robin, and I. Dajani, Origin of thermal modal instabilities in large mode area fiber amplifiers, Opt. Express 20, 11407-11422 (2012).

[16]J. Limpert, A. Liem, M. Reich, T. Schreiber, S. Nolte, H. Zellmer, A. Tünnermann, J. Broeng, A. Petersson, and C. Jakobsen, Low-nonlinearity single-transverse-mode ytterbium-doped photonic crystal fiber amplifier, Opt. Express 12, 13131319 (2004).

[17]S. Hädrich, T. Schreiber, T. Pertsch, J. Limpert, T. Peschel, R. Eberhardt, and A. Tünnermann, Thermo-optical behavior of rare-earth-doped lowNA fibers in high power operation, Opt. Express 14, 6091-6097 (2006). 
[18]J.W. Dawson, M.J. Messerly, R.J. Beach, M.Y. Shverdin, E.A. Stappaerts, A.K. Sridharan, P.H. Pax, J.E. Heebner, C.W. Siders, and C.P.J. Barty, Analysis of the scalability of diffraction-limited fiber lasers and amplifiers to high average power, Opt. Express 16, 13240-13266 (2008).

[19]X. Cheng, and J. Xu, Thermal and thermal-optical effects in high-power photonic crystal fiber lasers, Opt. Eng. 45, 124204 (2006).

[20]D.C. Brown and H.J. Hoffman, Thermal, stress, and thermo-optic effects in high average power double clad silica fiber lasers, IEEE J. Quantum Electron. 37, 207-217 (2001).

[21]P. Jund and R. Jullien, Molecular-dynamic calculation of the thermal conductivity of vitreous silica, Phys. Rev. B 59, 13707-13711 (1999).
[22]M. Sabaeian, Analytical solutions for anisotropic time-dependent heat equations with Robin boundary condition for cubic-shaped solid-state laser crystal, Appl. Opt. 51, 7150-7159 (2012).

[23]H.-L. Lee, Transient microbending loss by thermal loading in double-coated optical fibers, Opt. Eng. 42, 969-976 (2003).

[24]W. Xie, S.-Ch. Tam, Y.-L. Lam, K.S. Lai, R. Wu, Y. L. Lim, and E. Lau, Analysis of a dynamical procedure on diode-end-pumped solid-state lasers, IEEE J. Quantum Electron. 37, 1368-1372 (2001).

[25]J.F. Nye, Physical Properties of Crystals (Oxford University Press, London, 1967).

[26] J.M. Eggleston, T.J. Kane, K. Kuhn,; J. Unternahrer, and R.L. Byer The slab geometry laser - part I: Theory, IEEE J. Quantum Electron. 20, 289-301 (1984).

\title{
KAITIMO ITTAKOS DIDELĖS GALIOS FOTONINIO KRISTALO ŠVIESOLAIDINIO LAZERIO SKLINDANČIOMS MODOMS SKAITMENINIS MODELIAVIMAS
}

\author{
L. Mousavi ${ }^{\text {a }}$, M. Sabaeian ${ }^{b}$, H. Nadgaran ${ }^{\mathrm{c}}$ \\ ${ }^{a}$ Islamiškasis Azado universitetas, Dezfulis, Iranas \\ ${ }^{\mathrm{b}}$ Ahvazo sahido Chamrano universitetas, Ahvazas, Iranas \\ c Širazo universitetas, Širazas, Iranas
}

